Review

\title{
Poly(neutral red): Electrosynthesis, Characterization, and Application as a Redox Mediator
}

\author{
Rasa Pauliukaite, Christopher M. A. Brett* \\ Departamento de Química, Faculdade de Ciências e Tecnologia, Universidade de Coimbra, 3004-535 Coimbra, Portugal \\ *e-mail: brett@ci.uc.pt
}

Received: February 8, 2008

Accepted: April 8, 2008

\begin{abstract}
The synthesis by electropolymerization, the characterization, and applications of poly(neutral red) (PNR), including as a redox mediator, are reviewed. PNR's high electrical conductivity and its redox characteristics have led to special applications of the polymer, and it has been used for the development of electrochemical and optical sensors. Moreover, the attractive properties of PNR allow it to be applied in the development of electrochemical biosensors. Future perspectives are indicated.
\end{abstract}

Keywords: Neutral red, Poly(neutral red), Redox mediators, Electrochemical sensors, Electrochemical biosensors

DOI: 10.1002/elan.200804217

\section{Introduction}

Organic conducting polymers are finding increasing use in various fields of science and technology, such as primary and secondary batteries, metallization of dielectrics, antistatic coatings, electromagnetic shielding, electrochromic systems, etc. The most attractive property of conducting polymers in electrochemistry is their ability to catalyze electrode reactions - a thin layer of a conducting polymer is able to enhance the kinetics of electrode processes of some solution species. These electrocatalytic processes, at conducting polymer electrodes, represent a fast growing area of research, which may yield many unexpected applications in various fields of applied electrochemistry [1].

The phenazine dye, neutral red (NR; $N^{8}, N^{8}, 3$-trimethylphenazine-2,8,-diamine chloride; Fig. 1), is used for a variety of purposes such as biological staining [2], for medical purposes to investigate viruses [3], as a $\mathrm{pH}$ indicator in biochemical systems [4], in the determination of DNA using optical and electrochemical methods [5,6], for the evaluation of naturally-derived and synthetic biomaterials $[7,8]$, for the development of optical sensors [9], etc. Like other phenazine derivatives, in particular azur A [10], azur B [11], toluidine blue $\mathrm{O}$ [12], methylene blue [13], methylene green [14], phenosafranin [15], NR can be polymerized electrochemically and form a conductive polymer [16-21]. Recently, polymerized NR or poly(neutral red) (PNR) has been used as a redox mediator for sensors and biosensors [21-24].

This review discusses the electrochemical synthesis of PNR, the electrochemical properties of NR and PNR, its structure, as well as the application of PNR as a conducting polymer and as a redox mediator in electrochemical sensors and biosensors.

Electroanalysis 20, 2008, No. 12, 1275-1285<smiles>Cc1cc2nc3ccc(N(C)C)cc3nc2cc1N</smiles>

Fig. 1. Chemical structure of neutral red monomer.

\section{Polymerization of Neutral Red}

The first paper on the electrochemical polymerization of NR was published in 1970 by Nikolskii and co-authors [25]. They reported the dependence on $\mathrm{pH}$ of the oxidation potential of the system neutral red - leuco-neutral red in the region from $\mathrm{pH} 0.5$ to 11.5 . The data were divided into four linear ranges with the slopes as follows:

$$
\begin{aligned}
& 0.5 \leq \mathrm{pH} \leq 4.3-110 \mathrm{mV} \mathrm{pH}^{-1} \\
& 4.3 \leq \mathrm{pH} \leq 6.1-74 \mathrm{mV} \mathrm{pH}^{-1} \\
& 6.1 \leq \mathrm{pH} \leq 7.3-37 \mathrm{mV} \mathrm{pH}^{-1} \\
& 7.3 \leq \mathrm{pH} \leq 11.5-74 \mathrm{mV} \mathrm{pH}^{-1}
\end{aligned}
$$

The segments $1-3$ were shifted negatively as the total concentration of NR was increased. The authors attributed this shift to dimerization and tetramerization of the neutral red cation, i.e., the singly protonated form of the dye. From calculations in their previous paper, [26], the authors considered the following equilibria: 
<smiles>C=[In]c1ccc2nc3cc(C)c(N)cc3nc2c1</smiles><smiles>Cc1cc2c(cc1N)Nc1cc(N(C)C)ccc1[NH2+]2</smiles><smiles>Cc1cc2c(cc1N)Nc1cc(N(C)C)ccc1N2</smiles><smiles>Cc1cc2c(cc1N)Nc1cc(N(C)C)ccc1[NH+]2C(C)(C)C</smiles>

Fig. 2. Schematic mechanism of NR redox changes depending on $\mathrm{pH}$.

$$
\begin{aligned}
& \mathrm{NRH}^{+}+\mathrm{H}^{+}+2 \mathrm{e}^{-} \rightleftharpoons \mathrm{NRH}_{2} \\
& \mathrm{NRH}^{+} \rightleftharpoons \mathrm{NR}+\mathrm{H}^{+} \\
& \mathrm{NRH}_{3}^{+} \rightleftharpoons \mathrm{NRH}_{2}+\mathrm{H}^{+} \\
& \mathrm{NRH}_{4}{ }^{2+} \rightleftharpoons \mathrm{NRH}_{3}^{+}+\mathrm{H}^{+}
\end{aligned}
$$

where NR represents the neutral red molecule and $\mathrm{NRH}_{2}$ represents the leuco-neutral red molecule. The $\mathrm{p} K_{\mathrm{a}}$ values of the deprotonation reactions were determined as 6.7 for Reaction 6, 6.3 for Reaction 7, and 4.4 for Reaction 8 [26].

Combining this information on the protonation of NR and leuco-NR, the following overall reactions are obtained for the reduction of $\mathrm{NR}$ in different $\mathrm{pH}$ regions [27]:

$$
\begin{array}{ll}
0.5 \leq \mathrm{pH} \leq 4.4 & \mathrm{NRH}^{+}+3 \mathrm{H}^{+}+2 \mathrm{e}^{-} \rightleftharpoons \mathrm{NRH}_{4}^{2+} \\
4.4 \leq \mathrm{pH} \leq 6.3 & \mathrm{NRH}^{+}+2 \mathrm{H}^{+}+2 \mathrm{e}^{-} \rightleftharpoons \mathrm{NRH}_{3}^{+} \\
6.3 \leq \mathrm{pH} \leq 6.7 & \mathrm{NRH}^{+}+\mathrm{H}^{+}+2 \mathrm{e}^{-} \rightleftharpoons \mathrm{NRH}_{2} \\
6.7 \leq \mathrm{pH} \leq 11.5 & \mathrm{NR}+2 \mathrm{H}^{+}+2 \mathrm{e}^{-} \rightleftharpoons \mathrm{NRH}_{2}
\end{array}
$$

Reactions 9-11 involve the protonated cation but Reaction 12 involves the neutral NR molecule. It should be noted that $\mathrm{pH} 0.5$ and 11.5 are only significant as the limits of experimental information.

The electrochemical reactions leading to polymer formation are represented schematically in Figure 2, as suggested in [27]. The radicals obtained during NR oxidation initiate the polymerization process and the number of radicals formed defines the structure of the polymer: the more radicals formed, the more branched the polymer obtained [28]. The polymerization of NR is controlled not only by the applied potential, which is responsible for radical formation, but also by the $\mathrm{pH}[16-20,25-27]$, as is the case for other electrochemically-formed organic polymers [1,29-31]. The polymerization mechanism includes the formation of radicals, dimerization, and tetramerization of the monomers that then combine to give the polymer: the polymer is formed via $\mathrm{C}-\mathrm{N}$ couplings. This mechanism has been confirmed by IR spectroscopy, in agreement with FT Raman and ${ }^{1} \mathrm{H}$ NMR spectroscopic studies, and demonstrates that the polymerization of $\mathrm{NR}$ occurs through the $\mathrm{NH}_{2}$ groups of NR [22]. The possible structure of a tetramer is presented in Figure 3.

PNR growth seems to take place without alteration of the phenazine aromatic system of the monomer. Both the monomer and its derived polymer exhibit the same redox potential and a similar optical spectrum. The growth occurs through a linkage in one of the carbon atoms of the aromatic system of the monomer, the most probable being one of the ortho carbon atoms with respect to $-\mathrm{N}(\mathrm{R})_{2}$. A ring substitution with a strong electron attracting system, such as the cation-radical species, should induce a shift in the monomer redox potential towards more positive values, as indeed happened after NR polymerization [16].

The identity of counterions is very important in the polymerization of conducting organic polymers since they 


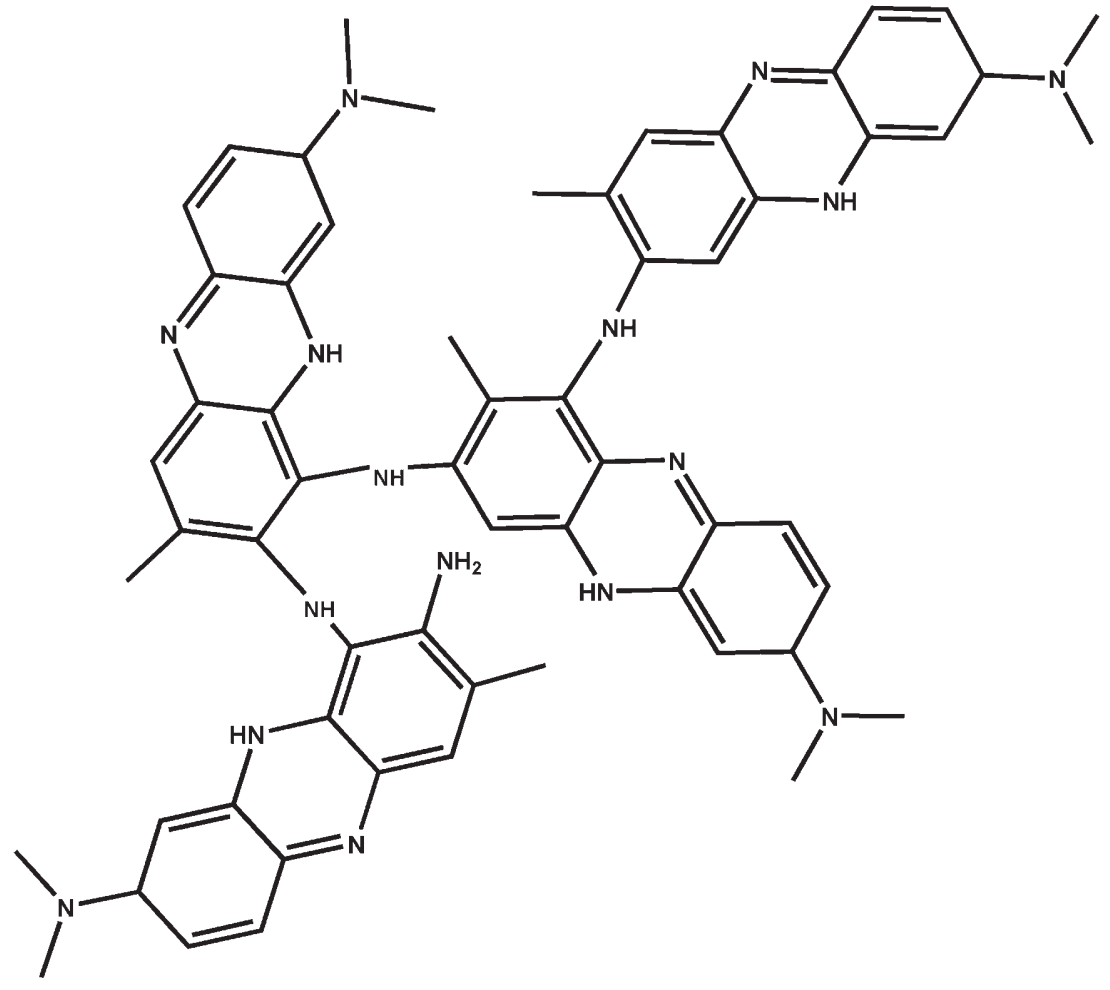

Fig. 3. Possible structure of NR tetramer.

can enhance its conductivity [25]. A scheme showing the mechanism of doping/de-doping of NR is presented in Figure 4. It has been found that nitrate ions are very important for PNR formation since $\mathrm{NO}_{3}{ }^{-}$catalyzes the electropolymerization of NR and stabilizes the polymer formed [17, 21, 32-34]. However, a PNR film can be successfully formed on a Pt substrate when $\mathrm{SO}_{4}{ }^{2-}$ is used in strong acidic medium $[18,20,22,35,36]$ as well as in Britton-Robinson buffer solution ( $\mathrm{pH}$ 1.5) without any additional electrolyte salt [37]. X-ray photoelectron spectroscopy (XPS) data proved that PNR deposited from sulfuric acid solution is $\mathrm{SO}_{4}{ }^{2-}$-doped and coupled with the protonated nitrogen of the polymer [18]. Fourier transform Raman spectra demonstrated that the PNR is a polycation where the positive charge is compensated by dopant anions [22]. Electron spin resonance (ESR) spectra of PNR supported the existence of radicals in the polymeric structures, and FTIR demonstrated the large changes in conjugation structure after NR electropolymerization [19].

Electrochemical polymerization of NR exhibits some characteristic redox peaks at certain potentials, as shown in Figure 5 [38], corresponding to reversible transformation of NR to leuco-NR at ca. $-0.5 \mathrm{~V}$ (6), doping/de-doping at around $0 \mathrm{~V}$ (Fig. 4), and irreversible NR oxidation and radical formation that initiates polymerization of the monomer at $0.8-1.0 \mathrm{~V}$ (Fig. 2). The peak potential depends on the $\mathrm{pH}$ and polymerization electrolyte composition as well as on the electrode substrate.

The electrochemical quartz crystal microbalance was used to study in situ the growth and redox transformations of
PNR films [33]. The mass changes that accompany the redox processes of the monomer were related to the adsorption of NR during oxidation and desorption of the adsorbed species during reduction, besides the mass increase due to formation of the polymer film during electropolymerization. In acidic media, the main redox reaction of PNR can be described as a relatively simple $2 \mathrm{e}^{-}, 2 \mathrm{H}^{+}$process (Eq. 10) assuming that the oxidized form is more hydrated than the reduced one, i.e., the film is more swollen in its oxidized state. Anions are also absorbed at higher $\mathrm{pH}$ values where the reduced form is partially deprotonated while the oxidized form is still fully protonated (Eq. 12). The EQCM data also showed that a kinetically irreversible oxidation process, which takes place at higher positive potentials, is accompanied by sorption of anions which leave the film if the potential is subsequently lowered. However, if the applied positive potential is too high film overoxidation occurs and the surface of the PNR film is slowly dissolved $[33,39]$.

Benito et al. [40], using EIS to characterize the PNR films, confirmed that both cations and anions participate as counterions in the electrochemical processes in the PNR films. The participation of monovalent anions is normally much more significant than $\mathrm{H}^{+}$(aq.), except at low $\mathrm{pH}$. Since the polymer is protonated to different degrees, depending on the $\mathrm{pH}$ of the bathing solution, protons can be strongly retained in the film structure and therefore, move slower than anions [40]. The role of electrolyte cations or anions is only to ensure electroneutrality, especially when the $\mathrm{pH}$ of the solution is not sufficiently acidic [32]. 
<smiles>Cc1cc2c(cc1N)Nc1ccc(N(C)[14CH3])cc1Nc1cc(N)c(C)cc1N2</smiles>

Fig. 4. Schematic mechanism of NR doping.

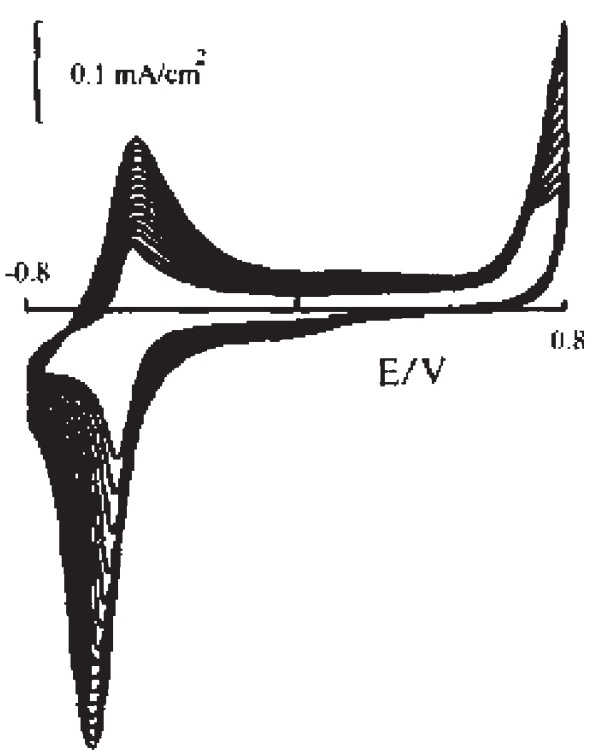

Fig. 5. Cyclic voltammograms of NR electropolymerization at glassy carbon electrode from solution, containing $0.4 \mathrm{mM} \mathrm{NR}$, $0.025 \mathrm{M}$ phosphate buffer, $\mathrm{pH} 6.0,0.1 \mathrm{M} \mathrm{NaNO}_{3}$, sweep rate $50 \mathrm{mV} \mathrm{s}^{-1}$, from [38] with permission of Elsevier.

The EQCM study also proved that the presence of molecular oxygen in the solution favors the electrogeneration reaction since more PNR is produced when polymerization solutions are not deoxygenated [32]. The relative participation of cation/anions during the charge compensation process in the region of the redox couple at ca. $0 \mathrm{~V}$ depended mainly on the $\mathrm{pH}$ of the solution, but also on the nature of the cations and anions. Thus, at $\mathrm{pH} 2.5-2.6$ the mass/charge ratio depended almost totally on the anion: according to the experimental data, smaller $\mathrm{Cl}^{-}$anions were preferable to the larger $\mathrm{NO}_{3}^{-}, \mathrm{I}^{-}$or $\mathrm{Br}^{-}$. At $\mathrm{pH} 4.5-4.7$ the values of the mass/charge ratio were larger for $\mathrm{NO}_{3}{ }^{-}$and $\mathrm{I}^{-}$ than $\mathrm{Cl}^{-}$. The different behavior can be explained by the fact that changing the $\mathrm{pH}$ from $2.5-2.6$ to $4.5-4.7$ also means a change in the polymer structure, since one of the $\mathrm{p} K_{\mathrm{a}}$ of the polymer lies between these $\mathrm{pH}$ values.
Both the electrolyte cations and the anions participate in the charge compensation at $\mathrm{pH} 4.5$ that can be postulated, for nitrate and sodium ions, as:

$\left[\mathrm{PNR}^{2+}, \mathrm{NO}_{3}^{-}\right]+2 \mathrm{e}^{-}+\mathrm{Na}^{+} \rightleftharpoons\left[\mathrm{PNR}, \mathrm{Na}^{+}\right]+\mathrm{NO}_{3}{ }^{-}$

nitrate being the most effective anion at this $\mathrm{pH}$ [32]. The peak potential values did not depend much on the nature of the electrolyte cation, anion or their concentration, but did depend on the $\mathrm{pH}$ value of the solution. Nevertheless, it has been shown that $\mathrm{K}^{+}$could substitute $\mathrm{H}^{+}$ions in the charge compensation mechanism [41].

The electrochemically active polymer films formed on a platinum electrode from solutions containing $\mathrm{H}_{2} \mathrm{SO}_{4}$ electrolyte had a somewhat similar electrochemical behavior to that of polyaniline films [18]. The electrochemical activity of the PNR film decreases with increasing $\mathrm{pH}$ of the polymerization solution from 1.0 to 4.0. Analysis of NR electropolymerization data revealed that protons and electrons take part in a $2: 1$ ratio in the reduction process, and that this ratio is $1: 1$ in the oxidation process. Additionally, the other redox couple of the polymer at higher positive potentials is due to polymer doping and has no participation of protons. PNR films deposited on Pt electrodes from sulfuric acid media cover the electrode with a nanowire microstructured network as seen in the scanning electron microscopy (SEM) images of Figure 6 [18].

Gold and indium tin oxide (ITO) have also been used as electrode substrates for PNR formation. PNR electrodeposition from $\mathrm{H}_{2} \mathrm{SO}_{4}$ solution, $\mathrm{pH}$ 1.0, was successful on both $\mathrm{Au}[42,43]$ and ITO electrodes [43] as well as at ITO electrodes from Britton - Robinson buffer, $\mathrm{pH} 5.15$ [44, 45]. However, the growth of the film at $\mathrm{Au}$ was slow, the peaks were badly defined, and no uniform film was obtained when NR was deposited from phosphate buffer solution, $\mathrm{pH} 5.5$, in the presence of potassium nitrate as supporting electrolyte [21].

The surface concentration of PNR was found to be significantly different at different electrode substrates, as well as depending on the number of electropolymerization 


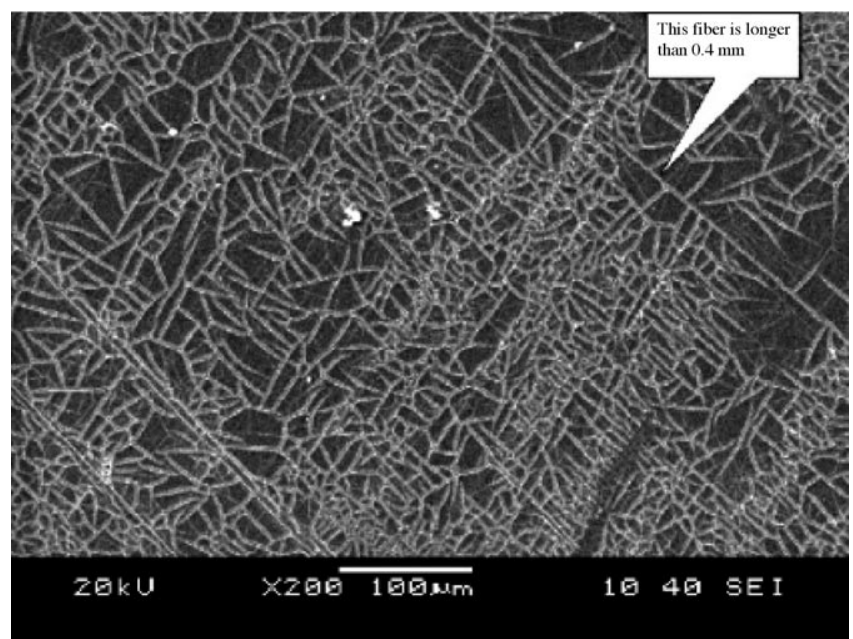

Fig. 6. SEM image of the PNR film deposited on Pt electrode, from [18] with permission of Elsevier.

cycles. For instance, at glassy carbon it was $2-3 \mathrm{nmol} \mathrm{cm} \mathrm{cm}^{-2}$

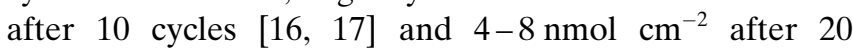
consecutive cycles [38, 46], at gold from $22 \mathrm{fmol} \mathrm{cm}^{-2}$ [47] to $32 \mathrm{nmol} \mathrm{cm} \mathrm{cm}^{-2}$ depending on the number of cycles and electropolymerization potential window [33, 42], and at carbon film $12.5 \mathrm{nmol} \mathrm{cm}{ }^{-2}$ after 15 potential cycles [48].

PM-FTIR (polarization modulation Fourier transform infrared) spectra obtained in situ for PNR films as a function of electrode potential generated on a gold electrode demonstrated that although the polymer film was relatively thick, the observed spectral features were weak, implying that the monomers are oriented almost parallel to the electrode surface. The amino groups of PNR are not protonated in spite of the acidic environment of the supporting electrolyte, according to the absorption bands for the $\mathrm{N}-\mathrm{H}$ bending vibration [43].

Apart from in aqueous solutions, PNR can also be successfully synthesized in non-aqueous solutions, for example in acetonitrile with the addition of $\mathrm{Bu}_{4} \mathrm{NClO}_{4}$ at Pt electrodes $[22,49]$ or from room temperature ionic liquids (RTIL) such as 1-butyl-3-methylimidazolium bis(trifluoromethane)sulfonimide, 1-butyl-1-methylpyrrolidinium bis(trifluoromethane) sulfonimide, and 1-butyl-3-methylimidazolium nitrate at carbon film electrodes [50, 51]. However, the last case showed that the applied potential is a crucial point: it was observed that PNR dissolved when potentials were more positive than $+0.5 \mathrm{~V}$. Moreover, such films were much thinner than those prepared in aqueous solutions since the polymerization of NR in the RTILs occurred in a slightly different way to those in aqueous solutions, due to the different solvent properties. The most similar polymerization CVs were obtained in $\mathrm{BmimNO}_{3}$ since the counter anion was smaller than bis(trifluoromethane)sulfonimide and the charge compensation in this case was easier [51]. Bard's group, following the results of electrogenerated chemiluminiscence, suggested a slightly different mechanism for NR electrochemical oxidation in non-aqueous acetonitrile solutions than that in Figure 2, since NR forms slightly different radicals than those in aqueous solutions, see the scheme of Figure 7 [49].

The polymerization of NR can be faster and the polymer properties better when the monomer is polymerized in the

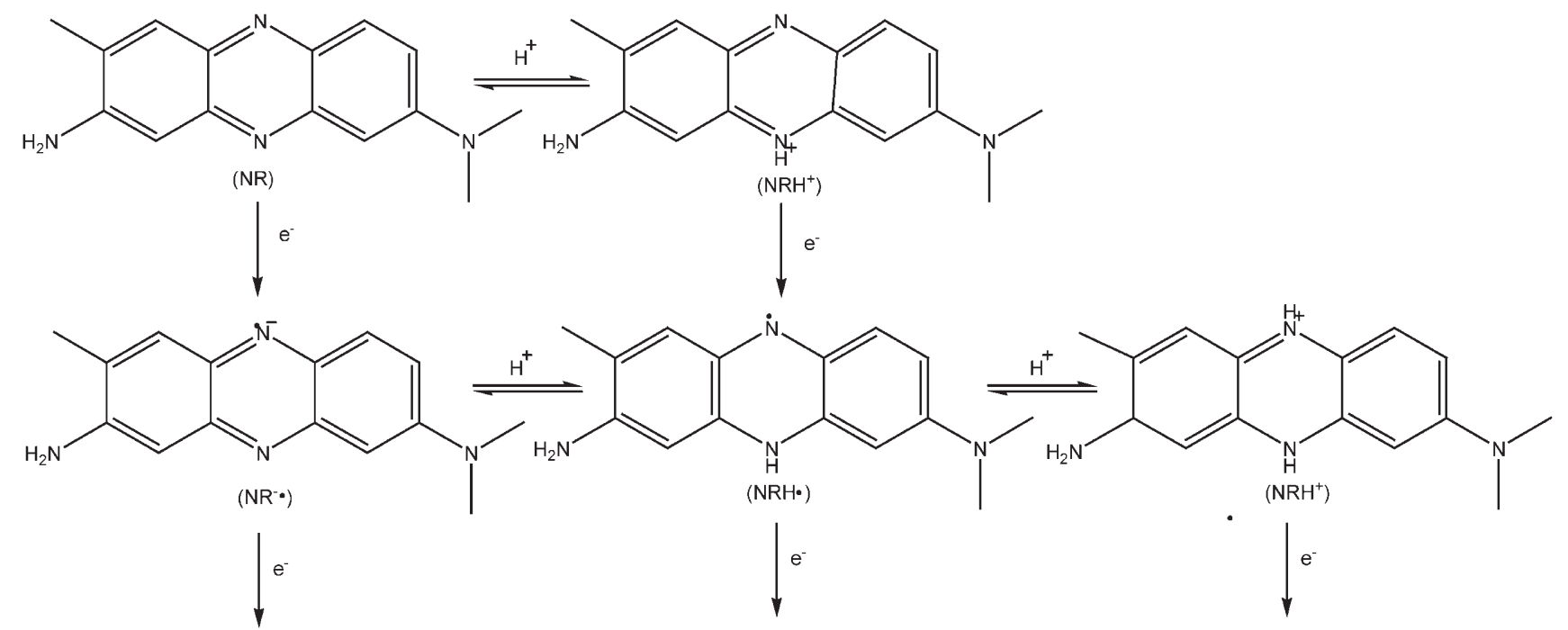<smiles>CC1=CC2Nc3ccc(N(C)C)cc3NC2=CC1N</smiles>

Fig. 7. Schematic of NR reduction mechanism in acetonitrile solution. 
presence of organic additives or of other polymers. The polymerization was found to be faster and the polymer had a higher electrochemical activity when ferrocenesulfonic acid was added to the deposition solution at $\mathrm{Pt}$ in $\mathrm{H}_{2} \mathrm{SO}_{4}$ : according to the data reported by Chen and Gao, ferrocenesulfonic acid acting as a dopant [20]. Although the addition of sulfoferrocenecarboxylic acid (SFCA) hardly changed the electrochemical properties of the polymer, the morphology of the PNR-SFCA film was different. It was supposed that the reason for these changes could be due to the erosion of the polymer during deposition [52]. In another study it was found that a polymer formed from aniline and NR had better electrochemical properties than polyaniline at $\mathrm{pH} 1.0$ in $\mathrm{H}_{2} \mathrm{SO}_{4}$ solution [53].

\section{Characterization of PNR Films}

Characterization of PNR films by various electrochemical, spectroscopic and microscopic techniques has shown clearly that the electrochemical properties of PNR depend on the potential cycling scheme during electropolymerization, as is the case with many conducting polymers, as well as on the electrode substrate. When the monomer can be oxidized during each potential cycle, the electrochemical properties of the resulting polymer show noticeable differences compared with the situation when monomer oxidation is impeded after the first two cycles by reducing the positive potential limit [21].

Potentiometric characterization of the PNR films showed that such polymer electrodes provide a linear and sensitive response to the hydronium ion generated for acids in aqueous solutions over a very broad $\mathrm{pH}$ range, 2-12; the exception was citric acid, where a strong deviation from linearity for $\mathrm{pH} 8-10$ was found [22]. In most cases studied, it was observed that the rate-determining process at PNR was rather complicated because voltammetric anodic and cathodic peaks of PNR had a different behavior depending mainly on the charge compensation process in the film [44]. Diffusion-controlled electrochemical oxidation was predominant at the polymer film electrochemically deposited at ITO [44] or gold [36] at low $\mathrm{pH}$ values and a masstransport controlled redox process was observed at PNR, on carbon film electrodes, at $\mathrm{pH} 5.5[21,48]$.

Recently carbon nanotubes have been used together with phenazine-type polymers [54]. PNR deposited on functionalized multiwalled carbon nanotubes (MWCNT) exhibited a slightly different electrochemical behavior than at other carbon-based electrodes [21,55]. The EQCM confirmed the incorporation of PNR on the functionalized MWCNTs. The investigation of such films by cyclic voltammetry showed a different behavior from that at glassy carbon in phosphate buffer, $\mathrm{pH}$ 4.0: NR/leuco-NR peaks were less well-defined at MWCNT, but the redox couple at $0.2 \mathrm{~V}$ for polymer doping/de-doping was much better defined than that at GC. Moreover, an additional redox wave appeared between these redox couples, probably due to two-step NR oxidation to leuco-NR [55, 56]. The PNR surface coverage concen- trations for different loads of functionalized MWCNTs clearly indicated that an increase in the amount of MWCNTs on GC led to an increase in the amount of PNR deposited on the electrode, due to the increase in the surface area. The electrochemical process was controlled by adsorption of electroactive species on the surface and depended on the MWCNT loading, i.e., at higher carbon nanotube loadings a mass-diffusion-controlled process was observed [55].

The good conductivity of polymer films enhances their application so that it is important to know the factors that determine PNR conductivity. From Figure 4 it is seen that both hydrogen ions and anions play a very important role in the electrochemical processes of and electron conduction through PNR films, since the reduced phenazine group partially loses its $p$-electronic character [32]. Thus, the solution $\mathrm{pH}$ is very important to the electron conduction process: an increase in $\mathrm{pH}$ causes a decrease in the size of the redox peaks in cyclic voltammetry and increases irreversibility. Since $\mathrm{H}^{+}$acts as counterion to the electrons, a decrease in its concentration in the film causes a decrease of the electrical conductivity through the film and makes the redox processes more irreversible [44]. It has also been observed that when more than a given thickness or deposited amount of PNR is reached, the polymer exhibits a very poor redox behavior. This is due to a low electronic conductivity, as has been demonstrated by EIS, so that the electrons can reach only a certain fraction of the redox centers of the PNR. The thick films have two zones: an inner redox layer and an outer layer which acts as a diffusion membrane with a different structure and morphology.

Polymer films deposited at $\mathrm{pH} 6.6$ in the presence of $\mathrm{KNO}_{3}$ have a typical conductivity of a semiconducting redox polymer [44]. The conductivity of PNR, deposited from solution acidic solution with $\mathrm{SO}_{4}{ }^{2-}$, was $1.7 \times 10^{-5} \mathrm{~S} \mathrm{~cm}^{-1}$ at $20^{\circ} \mathrm{C}[36,53]$ compared with the conductivity of polyaniline of $1.7 \times 10^{-3} \mathrm{~S} \mathrm{~cm}^{-1}$ [53]. Although the conductivity of PNR is lower than that of polyaniline, but PNR exhibits better redox properties and electron transfer capability which is a great advantage in its applications to electrochemical sensing systems.

\section{Application of NR and of PNR Films in Electrochemical Sensors and Biosensors}

The PNR properties discussed above suggest a broad field of possibilities to use this conducting polymer in different sensing systems. Moreover, the sensitivity and conductivity of this polymer can be controlled by changing the solution $\mathrm{pH}$. It is also an important advantage that this polymer is electrochemically active at physiological $\mathrm{pH}$.

\subsection{Sensors}

Neutral red monomer has been used in a number of applications as a solution additive or immobilized on the 


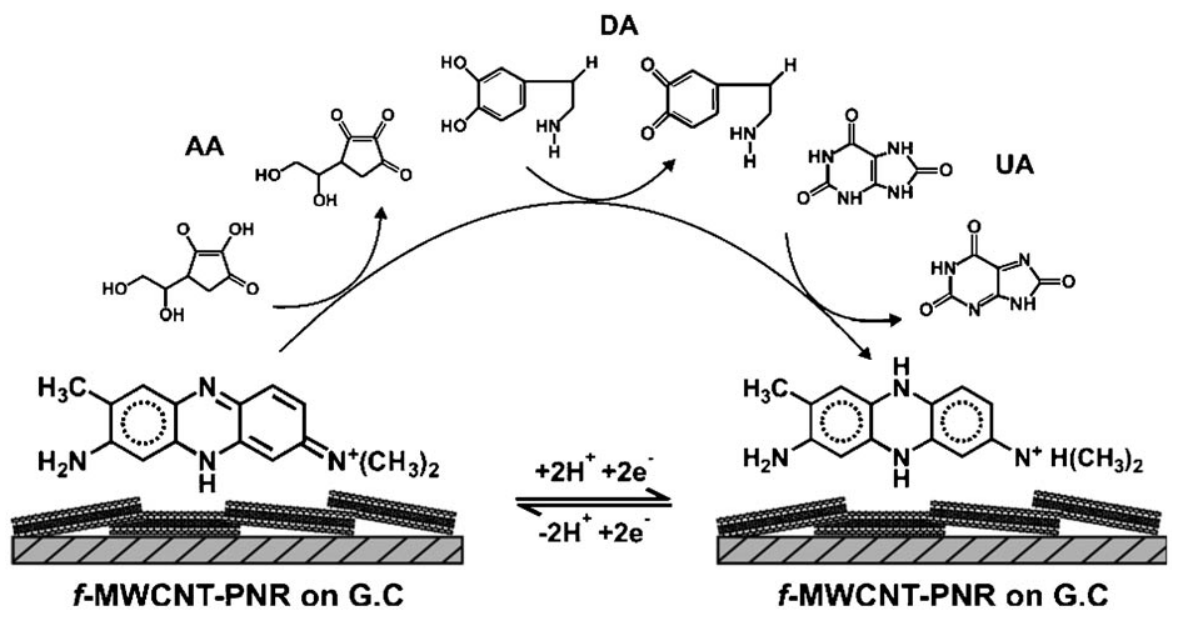

Fig. 8. Different interactions of AA, DA and UA at functionalized-MWCNT-PNR composite modified glassy carbon electrode, from [35] with permission of Elsevier.

surface of electrodes. For example, it has been employed as an electrochemical probe for the determination of heparin. The presence of heparin caused a decrease in the reduction peak current of NR, and an electrochemically inactive complex was formed by the electrostatic interaction of negatively-charged heparin with positively-charged NR. By exploiting the interaction of heparin with NR microamounts of heparin were determined with limit of detection 1.3 $\mathrm{mg} \mathrm{L}^{-1}$ [37].

A sensitive and simple optical sensor for the determination of lithocholic acid was developed, based on the fluorescence quenching of a NR/sulfonated $\beta$-cyclodextrin (s- $\beta$-CD) supramolecular complex immobilized in the polyelectrolyte multilayer film [9]. The multilayered thin film was prepared by a layer-by-layer deposition of s- $\beta-C D$ and cationic poly(allylamine) hydrochloride (PAH) on the surface of a quartz slide. A self-assembled fluorescent host was formed by the hydrophobic inclusion of NR/s- $\beta-C D$ and electrostatic interactions of NR with the s- $\beta$-CD immobilized on the multilayered film. The degree of quenching of NR fluorescence in NR/s- $\beta$-CD system was proportional to analyte concentration. The sensor was applied to the quantification of lithocholic acid with a linear range covering from 2 to $60 \mu \mathrm{mol} \mathrm{L}{ }^{-1}$ and a detection limit of $1 \mu \mathrm{mol} \mathrm{L}{ }^{-1}$. The sensor exhibited excellent reproducibility, reversibility and selectivity [9].

$\mathrm{NR}$, as an electron transfer mediator, was incorporated in an anode electrocatalyst system for methanol oxidation. The electrochemical performance of a $\mathrm{Pt} / \mathrm{NR} /$ graphite electrode was investigated by cyclic voltammetry and electrochemical impedance spectroscopy [56]. High electrocatalytic activity and good long-term cycle stability was achieved in the presence of NR. The corresponding results implied that electron transfer mediators may provide a new way to improve the electrochemical performance of electrodes in fuel cells.

Concerning PNR films, it was shown that they exhibit electrocatalytic properties [42, 57]. The electrocatalytic oxidation of $\mathrm{I}^{-}$was observed using the rotating ring-disk electrode (RRDE). The polymer film electrocatalyzed the reduction of $\mathrm{BrO}_{3}{ }^{-}$and $\mathrm{IO}_{3}{ }^{-}$in strongly acidic solutions and of $\mathrm{O}_{2}, \mathrm{NO}_{2}^{-}, \mathrm{SO}_{5}{ }^{2-}, \mathrm{IO}_{4}^{-}$, and $\mathrm{Cr}_{2} \mathrm{O}_{7}{ }^{2-}$ in acidic aqueous solutions. Nitric oxide can be oxidized to $\mathrm{NO}_{2}{ }^{-}$and then to $\mathrm{NO}_{3}{ }^{-}$, and reduced to $\mathrm{N}_{2} \mathrm{O}$ at PNR film electrodes [58], such electrodes have been covered with Nafion in order to eliminate all the interferences and have been employed to detect nitric oxide.

The PNR film was able to electrochemically regenerate nicotinamide adenine dinucleotide $\left(\mathrm{NAD}^{+} / \mathrm{NADH}\right)$, one of the challenges of bioelectrochemistry during the past three decades. Using PNR-modified electrodes, reversible voltammetric waves of $\mathrm{NAD}^{+} / \mathrm{NADH}$ reduction/oxidation were observed [38] and the equilibrium potential was determined. This was impossible using all previously-known catalytic and mediator systems. The unique PNR-based electrocatalyst allowed the determination of the standard potential of $\mathrm{NAD}^{+} / \mathrm{NADH}$ : $E^{\prime}$ ca. $-0.59 \mathrm{~V}$ vs. SCE at pH 6.0 [46].

As a conducting polymer material, PNR has also been used for the electrocatalytic oxidation of both dopamine and ascorbic acid. The catalytic currents were linearly related to dopamine and ascorbic acid concentration in the ranges 5$200 \mu \mathrm{mol} \mathrm{L}{ }^{-1}$ and $0.025-100 \mathrm{mmol} \mathrm{L}^{-1}$, respectively. Moreover, both analytes can be determined simultaneously by using the difference of the catalytic currents [34]. Much higher sensitivities for dopamine (DA), ascorbic acid (AA) and uric acid (UA) oxidation were found at functionalized MWCNTs modified with PNR in aqueous solutions at $\mathrm{pH}$ 4.0, see Figure 8. The sensitivity of the composite film towards ascorbic acid, dopamine and uric acid in differential pulse voltammetry was found to be 28,146 , and $84 \mathrm{nA}$ $\mu \mathrm{mol}^{-1} \mathrm{~L}$, respectively [35].

Besides these compounds, PNR is sensitive to many carboxylates, such as acetate, adipate, benzoate, citrate, glutarate, malate, malonate, mandelate, oxalate, salicylate, succinate, tratrate, and terephthalate, in the $\mathrm{pH}$ rage $7.0-$ 8.5, in aqueous and non-aqueous solutions [22]. However, citrate showed a near-Nernstian response at PNR-modified 
electrodes and the broadest linear concentration range of all compounds tested. Owing to the specific behavior of citrate ion on PNR electrodes, especially at $\mathrm{pH} 8.5$, the selectivity coefficients $\log K_{\mathrm{Citrat} / \mathrm{J}}^{\text {pot }}$ were determined for various carboxylates, and were found to be -1.82 (glutarate) $>$ -1.30 (adipate) $\approx-1.28$ (malonate) $>-0.86$ succinate at PNR prepared in aqueous solutions, and -1.68 (glutarate) $>-1.49$ (malonate) $>-1.30$ (adipate) $>-0.71$ (succinate) at PNR prepared in non-aqueous solutions. As seen, the selectivity pattern was slightly different on the PNR electrodes prepared in aqueous and non-aqueous solution, as a consequence of different morphologies of the polymeric layers obtained under different conditions. It was also found that the PNR films could successfully act as precise and selective potentiometric sensors for citrate ion, even in natural samples. Furthermore, high concentrations of ascorbic acid, glucose and sucrose had no detrimental influence on citrate determination in soft drinks [22].

A paraffin-soaked graphite electrode modified with a PNR film and covered with a gelatin layer has been used as a $\mathrm{H}_{2} \mathrm{O}_{2}$ sensor. The sensor exhibited a linear range from $20 \mu \mathrm{mol} \mathrm{L}{ }^{-1}$ to $25 \mathrm{mmol} \mathrm{L}^{-1}$. The response time and the detection limit were $30 \mathrm{~s}$ and $18 \mu \mathrm{mol} \mathrm{L}{ }^{-1}$, respectively. The storage stability of such a sensor at $4{ }^{\circ} \mathrm{C}$ was four months [59].

\subsection{Redox Mediator for Biosensors}

In the last few years, PNR has become attractive in the field of electrochemical biosensors since it can be used both as a redox mediator for enzymatic reactions and for electrochemical reduction/oxidation of the products of the enzymatic reactions.

The mechanism of the mediation process is rather complicated [21]. Glucose biosensors with PNR redox mediator and immobilized GOx showed a mechanism that comprises two processes involving hydrogen peroxide reduction and an anodic process, possibly regeneration of FAD cofactor by oxidation at PNR. The results of this competition depend on the nature of the enzyme and the applied potential, which influenced the mediation mechanism. The details of the method of electropolymerization to produce the PNR film have hardly any influence on biosensor performance. The type of enzyme immobilization plays a more important role. Enzyme encapsulation in a solgel layer placed over the PNR film slightly dissolves PNR during the coating procedure and so distributes it in the bulk sol-gel enzyme layer, allowing an easier path for electron transfer and facilitating hydrogen peroxide reduction. Such dissolution also occurs to some extent inside glutaraldehyde (GA) cross-linked enzyme layers. Because the sol-gel entrapped enzyme layer is thicker than that obtained by cross-linking with GA, these effects were more noticeable in sol-gel encapsulation [21].

These PNR-mediated biosensors were characterized electrochemically in model solutions prior to application to natural samples [21, 23, 48] and by using atomic force microscopy (AFM) [60]. Highly oriented pyrolytic graphite was used as an electrode substrate for AFM investigations. HOPG electrodes modified with PNR as mediator, with and without sol-gel-encapsulated GOx on the top of the PNR layer, were characterized by AFM. The PNR film dissolved in the oxysilane solution and the PNR amino groups interact with the sol-gel. This is particularly the case with 3glycidoxypropyl-trimethoxysilane (GOPMOS), which has an epoxy ring present at the end of the glycidoxy group, enhancing the PNR-GOPMOS hydrophobic interactions. In this way, the immobilized sol-gel film becomes smoother and its structure possesses smaller pores, even in the presence of GOx molecules, in this way reducing enzyme leaching and increasing biosensor operational and storage stability [60].

Glucose is an important compound taking part in the metabolism of different organisms and a source of energy. Owing to the importance of the monitoring of glucose, quite a lot of research is devoted to the development of glucose biosensors. For this reason, the investigation of PNR as redox mediator has been mainly associated with the development of glucose biosensors, but biosensors have also been reported for monitoring other enzyme substrates, such as hydrogen peroxide, pyruvate, acetaldehyde, ethanol, etc., see Table 1 . PNR has mainly been applied as a redox mediator in the development of electrochemical enzyme biosensors by Brett et al. [21, 23, 24, 48, 50, 51, 60, 62, 63, 6668 ], and a few investigations have been done by other groups $[59,61,64,69]$. As seen from Table 1 , the majority of the biosensors operate in the potential range from -0.35 to $-0.25 \mathrm{~V}$. At these potentials, PNR appears to be an excellent redox mediator for enzyme biosensors, especially in acidic and neutral media, but as a good conducting material also enables the direct reaction of some carboxylic acids/carboxylates that interfere with the signal obtained in natural samples. To solve this problem, protective membranes, such as carboxylated poly(vinyl chloride) [63], polyurethane [63] or Nafion [69], have been employed.

Bienzymatic PNR-mediated biosensors have also been developed, see Table 1 . The second enzyme in bienzymatic biosensors can be used to regenerate the first enzyme, thus extending the lifetime of the first enzyme. An example is the case of AlcOx plus NADHOx - the latter enzyme regenerating the cofactor of the first enzyme [68]. NADH could also be regenerated at PNR, but at rather negative potentials $(-0.6 \mathrm{~V})$, where some carboxylates can interfere with the biosensor signal, and thus, the second enzyme solves the problem.

The second enzyme can also be used to oxidize the product of the first enzymatic reaction in order to facilitate electrochemical detection as in:

$$
\begin{gathered}
\mathrm{CH}_{2}(\mathrm{OH})-\mathrm{CH}(\mathrm{OH})-\mathrm{CH}_{2}(\mathrm{OH})+\mathrm{ATP} \stackrel{\mathrm{GK}, \mathrm{MgCl}_{2}}{\longrightarrow} \\
\mathrm{CH}_{2}(\mathrm{OH})-\mathrm{CH}(\mathrm{OH})-\mathrm{CH}_{2}\left(\mathrm{OPO}_{3} \mathrm{H}_{2}\right)+\mathrm{ADP} \\
\mathrm{CH}_{2}(\mathrm{OH})-\mathrm{CH}(\mathrm{OH})-\mathrm{CH}_{2}\left(\mathrm{OPO}_{3} \mathrm{H}_{2}\right)+\mathrm{PNR} \stackrel{\mathrm{GPOx}}{\longrightarrow} \\
\mathrm{CH}_{2}(\mathrm{OH})-\mathrm{CO}-\mathrm{CH}_{2}\left(\mathrm{OPO}_{3} \mathrm{H}_{2}\right)+\mathrm{PNRH}_{2}
\end{gathered}
$$


Table 1. Electrochemical biosensors constructed with PNR as redox mediator and their bioanalytical properties.

\begin{tabular}{|c|c|c|c|c|c|c|c|}
\hline Substrate & Enzyme & Electrode composition & $\begin{array}{l}\text { Applied } \\
\text { potential } \\
\text { (V vs. SCE) }\end{array}$ & $\begin{array}{l}\text { Linear range } \\
\left(\mathrm{mmol} \mathrm{L}^{-1}\right)\end{array}$ & 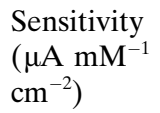 & $\begin{array}{l}K_{\mathrm{m}} \\
(\mathrm{mM})\end{array}$ & $\begin{array}{l}\text { Refer- } \\
\text { ence }\end{array}$ \\
\hline Glucose & GOx & CFE/PNR/GOx-BSA-GA & -0.35 & $0.09-1.80$ & 1.5 & 2.4 & [23] \\
\hline Glucose & GOx & CFE/PNR/GOx-BSA-GA & -0.35 & Up to 1.2 & 26.5 & 5.1 & [24] \\
\hline Glucose & GOx & CFE/PNR/GOx-sol-gel & -0.35 & Up to 1.0 & 4.0 & 3.2 & [24] \\
\hline Glucose & GOx & CFE/PNR/GOx-(sol-gel-RTIL) & -0.25 & $0.05-1.10$ & 3.1 & 2.2 & {$[50]$} \\
\hline Glucose & GOx & $\begin{array}{l}\text { CFE/PNR/GOx-BSA-GA } \\
\text { in RTIL medium }\end{array}$ & $-0.35[\mathrm{a}]$ & $0.05-1.70$ & 1.4 & 2.7 & {$[50]$} \\
\hline Glucose & GOx & GCE/MWCNT/PNR/GOx-BSA-GA & -0.20 & $0.05-10.00$ & 3.2 & - & [60] \\
\hline Glucose & GOx & CFE/PNR/GOx-sol-gel & -0.25 & $0.05-0.60$ & 0.3 & 1.2 & [62] \\
\hline Glucose & GOx & CFE/PNR/GOx-sol-gel/PU & -0.25 & $0.05-0.50$ & 0.6 & 1.7 & {$[63]$} \\
\hline $\mathrm{H}_{2} \mathrm{O}_{2}$ & HRP & GCE/PNR(NW)-HRP & -0.10 & $0.001-8.000$ & 318 & - & [64] \\
\hline $\mathrm{H}_{2} \mathrm{O}_{2}$ & HRP & GCE/NR-HPR-GA & $-0.40[\mathrm{~b}]$ & Up to 0.5 & 80 & - & {$[65]$} \\
\hline Pyruvate & $\mathrm{PyOx}$ & CFE/PNR/PyOx-BSA-GA & -0.25 & $0.09-0.60$ & 0.1 & 0.8 & [23] \\
\hline Ethanol & AlcOx & CFE/PNR/AlcOx-BSA-GA & -0.30 & Up to 0.6 & 8.5 & 2.1 & {$[66]$} \\
\hline Glycerol & GK + GPOx & CFE/PNR/GK-GPOx-GA & -0.35 & $0.02-0.14$ & 6.4 & 0.2 & [67] \\
\hline \multirow[t]{2}{*}{ Acetaldehyde } & AldOx + & CFE/PNR/AldOx-NADHOx-GA & -0.50 & Up to 0.1 & 285 & 0.2 & {$[68]$} \\
\hline & NADHOx & CFE/PNR/AldOx-NADHOx-sol-gel & -0.40 & $0.01-0.06$ & 85 & 1.4 & \\
\hline
\end{tabular}

[a] potential is given vs. pseudo $\mathrm{Ag} / \mathrm{AgCl}$, [b] vs. $\mathrm{Ag} / \mathrm{AgCl}$

Glycerol kinase, in the presence of ATP, transforms glycerol to glycerol-3-phosphate and $\mathrm{MgCl}_{2}$ is the enzyme-activating compound (Eq. 14). Glycerol phosphate is then oxidized to glyceron-3-phosphate by glycerol phosphate oxidase (Eq. 15) and the enzyme is regenerated at PNR [23].

An array of three different enzyme biosensors was used to monitor three analytes simultaneously. The biosensors were applied in a flow-injection analysis (FIA) system with an enzyme electrode array based on NR-doped silica (NRDS) nanoparticles as electrocatalyst. These uniform NRDS nanoparticles (ca. $50 \mathrm{~nm}$ diameter) were prepared by a water-in-oil microemulsion method. NRDS showed high biocompability and maintained its high electroactivity, while the external nanosilica surface prevented NR from leaching out into the aqueous solutions. These nanoparticles were mixed with GOx, LOx (lactate oxidase), or GLOx (Lglutamate oxidase), and immobilized on three different carbon-disk electrodes. A thin Nafion film was coated on top of the enzyme layer to prevent interferences. Flow-injection analysis with the NRDS-enzyme electrode array enabled simultaneous monitoring of glucose, lactate and L-glutamate in blood [69].

\section{Conclusions and Future Perspectives}

Electrochemical polymerization of neutral red, as well as of other phenazine dyes, introduced a novel kind of redox mediator with direct electron transfer properties. The properties of the monomer are retained, but whereas the former is soluble in water and can be washed from the electrode, polymerized neutral red is slightly soluble only in some organic solvents. PNR is an attractive conducting polymer due to its easy preparation and low cost. Depending on the deposition conditions, PNR can be obtained as a solid film, as nanowires or as a thin network at the electrode surface. PNR electrochemical polymerization can be controlled by changing $\mathrm{pH}$, electrolyte salt, and applied potential range as well as the number of cycles and scan rate by potential cycling.

PNR has been used as a redox mediator in the construction of electrochemical sensors and biosensors and shows excellent mediation properties. The mechanism of action in biosensors is quite complicated because different anodic and cathodic processes compete, the dominating one depending on the electrolyte solution composition as well as on the applied potential. The mechanism of polymer formation and mediation mechanisms need to be studied in more detail.

Furthermore, this conducting polymer has great potential for various analytical and sensing applications as described, and these possibilities can usefully be investigated more intensively. An interesting avenue is to exploit PNR more efficiently and effectively in sensors and biosensors. The advantages already demonstrated imply that it can be used as a nanostructured polymer or in thin nanometre-thick films, as well as being combined with metallic nanoparticles such as $\mathrm{Au}$ and $\mathrm{Pt}$, to improve conductivity and functionality or with carbon nanotubes.

\section{Acknowledgements}

Financial support from Fundação para a Ciência e Tecnologia (FCT), Portugal, PTDC/QUI/65255/2006, POCI 2010 (co-financed by the European Community Fund FEDER) and ICEMS (Research Unit 103), is gratefully acknowledged. RP thanks FCT for a postdoctoral fellowship (SFRH/BPD/27075/2006). 


\section{Glossary of Symbols}

$\begin{array}{ll}\text { ADP } & \text { adenosine diphosphate } \\ \text { AlcOx } & \begin{array}{l}\text { alcohol oxidase } \\ \text { AldOx }\end{array} \\ \text { aldehyde oxidase } \\ \text { ATP } & \text { adenosine triphosphate } \\ \text { BSA } & \text { bovine serum albumin } \\ \text { CFE } & \text { carbon film electrode } \\ \text { FIA } & \text { flow-injection analysis } \\ \text { GA } & \text { glutaraldehyde } \\ \text { GCE } & \text { glassy carbon electrode } \\ \text { GK } & \text { glycerol kinase }\end{array}$

GOPMOS 3-glycidoxypropyl-trimethoxysilane

GLOx L-glutamate oxidase

GPOx glycerol-3-phosphate oxidase

HPR horseradish peroxidize

LOx lactate oxidase

MWCNT multi walled carbon nanotubes

NADH nicotinamide adenine dinucleotide

NADHOx nicotine adenine dinucleotide oxidase

NR neutral red

PAH poly(allylamine) hydrochloride

PM-FTIR polarization modulation Fourier transform

spectros- infrared spectroscopy

copy

PNR poly(neutral red)

PNR(NW) poly(neutral red) nanowires

PU polyurethane

PyOx pyruvate oxidase

RRDE rotating ring-disk electrode

RTIL room temperature ionic liquids

s- $\beta$-CD sulfonated $\beta$-cyclodextrin

SEM scanning electron microscopy

SFCA sulfoferrocenecarboxylic acid

Sol-gel silica-based xerogel

XPS X-ray photoelectron spectroscopy

\section{References}

[1] A. Malinauskas, Synth. Met. 1999, 107, 75.

[2] M. Guttenberg, Plant Soil 2000, 226, 211.

[3] P. J. Cardona, C. Y. Soto, B. Giquel, G. Augustí, E. Guirado, T. Sirakova, P. Kolattukudy, E. Julián, M. Luquin, Microb. Infect. 2006, 8, 183.

[4] V. Ricci, P. Sommi, R. Fiocca, V. Necchi, M. Ramano, E. Solcia, Biochem. Biophys. Res. Commun. 2002, 292, 167.

[5] T. Mammone, D. Gan, D. Collins, R. A. Lockshin, K. Marenus, D. Maes, Cell Biol. Toxic. 2000, 16, 293.

[6] Y. Ni, D. Lin, S. Kokot, Anal. Biochem. 2006, 352, 231.

[7] J. L. Pariente, B. S. Kim, A. Atala, J. Urol. 2002, 167, 1867.

[8] V. Vince, M. A. Thil, C. Veraart, I. M. Colin, J. Delbeke, J. Biomater. Sci. Polym. Edn. 2004, 15, 173

[9] Y. Yang, X. Yang, Y. L. Liu, Z. M. Liu, H. F. Yang, G. L. Shen, R. Q. Yu, J. Photochem. Photobiol. A 2005, 171, 137.

[10] C. Chen, S. Mu, J. Appl. Polym. Sci. 2003, 88, 1218.

[11] D. Shan, S. Mu, B. Mao, Electroanalysis 2001, 13, 493.

[12] Y. Dilgin, L. Gorton, G. Nisli, Electroanalysis 2007, 19, 286.

[13] T. Komura, G. Y. Niu, T. Yamaguchi, M. Asano, A. Matsuda, Electroanalysis 2004, 16, 1791.
[14] V. Svoboda, M. J. Cooney, C. Rippolz, B. Y. Liaw. J. Electrochem. Soc. 2007, 154, D113.

[15] T. Komura, M. Ishihara, T. Yamaguchi, K. Takahashi. $J$. Electroanal. Chem. 2000, 493, 84.

[16] D. D. Schlereth, A. A. Karyakin. J. Electroanal. Chem. 1995, 395, 221.

[17] A. A. Karyakin, E. E. Karyakina, H. L. Schmidt. Electroanalysis 1999, 11, 149.

[18] C. Chen, Y. Gao. Electrochim. Acta 2007, 52, 3143.

[19] C. Yang, J. Yi, X. Tang, G. Zhou, Y. Zeng, React. Funct. Polym. 2006, 66, 1336 .

[20] C. Chen, Y. Gao, Electrochim. Acta 2007, 52, 7322.

[21] R. Pauliukaite, M. E. Ghica, M. Barsan, C. M. A. Brett, J. Solid State Electrochem. 2007, 11, 899.

[22] G. Broncová, T. V. Shishkanova, P. Matějka, R. Volf, V. Král, Anal. Chim. Acta 2004, 511, 197.

[23] M. E. Ghica, C. M. A. Brett, Electroanalysis 2006, 18, 748.

[24] M. M. Barsan, J. Klinčar, M. Batič, C. M. A. Brett, Talanta 2007, 71, 1893.

[25] B. P.Nikolskii, V. V. Palchevskii, L. A. Polyanskaya, A. G. Rodichev, Dokl. Akad. Nauk SSSR 1970, 194, 1334.

[26] B. P. Nikolskii, V. V. Palchevskii, L. A. Polyanskaya, V. V. Boriskin., Dokl. Akad. Nauk SSSR 1970, 193, 352.

[27] C. S. Halliday, D. B. Matthews, Aust. J. Chem. 1983, 36, 507.

[28] J. P. Pouget, Z. Oblakowski, Y. Nogami, P. A. Albouy, M. Laridjani, E. J. Oh, Y. Min, A. G. MacDiarmid, J. Tsukamoto, T. Ishiguro, A. J. Epstein, Synth. Met. 1994, 65, 131.

[29] C. M. A. Brett, A. M. C. F. Oliveira Brett, J. L. C. Pereira, C. Rebelo, J. Appl. Electrochem. 1993, 23, 332.

[30] C. Thiemann, C. M. A. Brett, Synth. Met. 2001, 123, 1.

[31] C. Thiemann, C. M. A. Brett, Synth. Met. 2001, 125, 445.

[32] D. Benito, C. Gabrielli, J. J. García-Jareno, M. Keddam, H. Perrot, F. Vicente, Electrochim. Acta 2003, 48, 4039.

[33] G. Inzelt, E. Csahók, Electroanalysis 1999, 11, 744.

[34] Y. Sun, B. Ye, W. Zhang, X. Zhou, Anal. Chim. Acta 1998, $363,75$.

[35] U. Yogeswaran, S. M. Chen, Electrochim. Acta 2007, 52, 5985.

[36] C. X. Chen, H. P. Zhu, Bull. Electrochem. 2002, 18, 247.

[37] W. Sun, K. Jiao, J. Han, L. Lu, Anal. Lett. 2005, 38, 1137.

[38] A. A. Karyakin, O. A. Bobrova, E. E. Karyakina, J. Electroanal. Chem. 1995, 399, 179.

[39] C. Chen, Y. Gao, Rus. J. Electrochem. 2007, 43, 267.

[40] D. Benito, C. Gabrielli, J. J. García-Jareño, M. Keddam, H. Perrot, F. Vicente, Electrochem. Commun. 2002, 4, 613.

[41] Z. Puskás, G. Inzelt, Electrochim. Acta 2005, 50, 1481.

[42] E. I. Sáez, R. M. Corn, Electrochim. Acta 1993, 38, 1619.

[43] S. M. Chen, K. C. Lin, J. Electroanal. Chem. 2001, 511, 101.

[44] D. Benito, J. J. García-Jareño, J. Navarro-Laboulais, F. Vicente, J. Electroanal. Chem. 1998, 446, 47.

[45] F. Vicente, J. J. García-Jareño, D. Benito, J. Agrisuelas, J. New Mater. Electrochem. Sys. 2003, 6, 267.

[46] A. A. Karyakin, Y. N. Ivanova, E. E. Karyakina, Electrochem. Commun. 2003, 5, 677.

[47] S. M. Chen, Y. H. Fa, J. Electroanal. Chem. 2003, 553, 63.

[48] M. M. Barsan, E. M. Pinto, C. M. A. Brett. Electrochim. Acta, 2008, 74, 1505.

[49] J. P. Choi, A. J. Bard, J. Electroanal. Chem. 2004, 573, 215.

[50] R. Pauliukaite, A. P. Doherty, K. D. Murnaghan, C. M. A. Brett. J. Electroanal. Chem. 2008, 616, 14.

[51] R. Pauliukaite, A. P. Doherty, K. D. Murnaghan, C. M. A. Brett. Electroanalysis 2008, 20, 485.

[52] C. X. Chen, Y. H. Gao, Polymer 2007, 48, 5572.

[53] C. X. Chen, Y. H. Gao, Mat. Chem. Phys. 2007, 102, 24.

[54] C. A. Thorogood, G. G. Wildgoose, A. Crossley, R. M. J. Jacobs, J. H. Jones, R. G. Compton, Chem. Mater. 2007, 19, 4964.

[55] U. Yogeswaran, S. M. Chen, Electrochim. Acta 2007, 52, 5985. 
[56] X. Zhong, J. Chen, B. Liu, Y. Xu, Y. Kuang, J. Solid State Electrochem. 2007, 11, 463.

[57] C. Gouveia-Caridade, C. M. A. Brett, unpublished data.

[58] X. Tang, C. Fang, B. Yao, W. Zhang, Microchem. J. 1999, 62, 377.

[59] G. R. Zhang, H. Y. Liu, Y. L. Wan, Chin. J. Anal. Chem. 2002, 30, 1237.

[60] A. M. Chiorcea Paquim, R. Pauliukaite, C. M. A. Brett, A. M. Oliveira Brett, in press, DOI: 10.1016/j.bios.2008.04.001.

[61] F. Qu, M. Yang, J. Chen, G. Shen, R. Yu, Anal. Lett. 2006, 39, 1785.

[62] R. Pauliukaite, A. M. Chiorcea Paquim, A. M. Oliveira Brett, C. M. A. Brett, Electrochim. Acta 2006, 52, 1.
[63] R. Pauliukaite, M. Schoenleber, P. Vadgama, C. M. A. Brett, Anal. Bioanal. Chem. 2008, 20, 485.

[64] F. Qu, M. Yang, J. Jiang, K. Feng, G. Shen, R. Yu, Electrochem. Commun. 2007, 9, 2596.

[65] B. S. B. Salomi, C. K. Mitra, Biosens. Bioelectron. 2007, 22, 1825.

[66] M. M. Barsan, C. M. A. Brett, Talanta 2008, 74, 1505.

[67] M. E. Ghica, C. M. A. Brett, Anal. Lett. 2006, 39, 1527.

[68] M. E. Ghica, R. Pauliukaite, N. Marchand, E. Devic, C. M. A. Brett. Anal. Chim. Acta 2007, 591, 80.

[69] Q. Wan, F. F. Zhang, M. C. Liu, Z. Q. Zhu, Y. Z. Xian, L. T. Jin, Chin. J. Chem. (abstract) 2005, 23, 280.

Wiley's

World of

Analytical Science

Helping researchers in chemistry, life science environmental science, medical and pharmaceutical science discover more

\section{www.interscience.wiley.com/analytical-science}

Journals

Databases

Backfile Collection

Free Access Websites

Free Magazines

Online Books

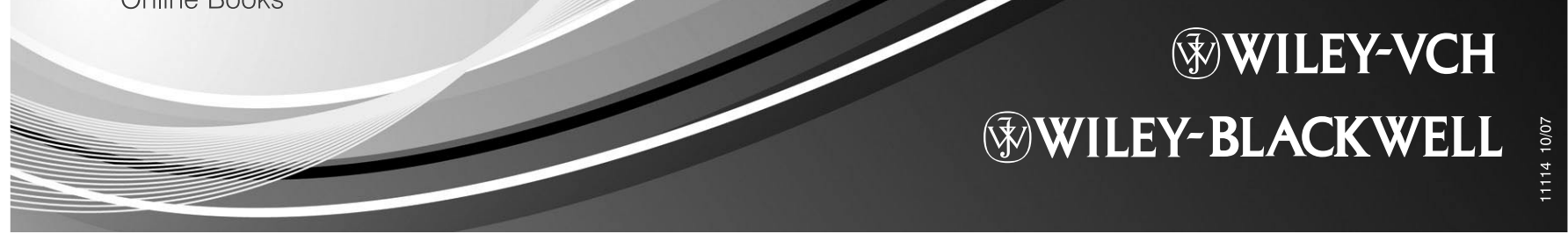

Electroanalysis 20, 2008, No. 12, 1275-1285 www.electroanalysis.wiley-vch.de @ 2008 WILEY-VCH Verlag GmbH \& Co. KGaA, Weinheim 